\title{
Os modelos conciliatórios de solução de conflitos e a "violência doméstica"
}

\author{
Guita Grin Debert** \\ Marcella Beraldo de Oliveira***
}

\begin{abstract}
Resumo
Os modelos conciliatórios de solução de conflitos têm ganhado uma importância cada vez maior nas propostas interessadas em dar celeridade ao Judiciário e ampliar o acesso da população à justiça. Esse artigo propõe uma reflexão sobre esse modelo, pautado no acordo e na conciliação, quando está em jogo a violência doméstica. Tomando como base estudos etnográficos sobre a Delegacia de Defesa da Mulher e os Juizados Especiais Criminais, o argumento central é que a conciliação ganha conteúdos muito distintos nessas duas instâncias do sistema de justiça. O contraste entre valores e simbologias postas em ação no fluxo dos processos nessas duas instâncias oferece elementos para a compreensão do contexto que levou à promulgação da Lei Maria da Penha, sancionada no dia 7 de agosto 2006, que retirou do âmbito dos Juizados Especiais Criminais os delitos que envolvem violência doméstica e familiar contra a mulher.
\end{abstract}

Palavras-chave: Violência Doméstica, Conciliação, Delegacia de Defesa da Mulher, Juizados Especiais Criminais.

\footnotetext{
* Recebido para publicação em agosto de 2006, aceito em fevereiro de 2007.

** Antropóloga, professora Titular do Departamento de Antropologia e coordenadora do Núcleo de Estudos de Gênero - Pagu, ambos da Unicamp. ggdebert@uol.com.br

***** Doutoranda em Ciências Sociais no Instituto de Filosofia e Ciências Humanas da Unicamp.marcellaberaldo@hotmail.com
} 
Solução de conflitos e a "violência doméstica"

"Domestic Violence" and Different Forms of Conciliation

\begin{abstract}
Alternative conflict resolution based on forms of conciliation have been identified as a possible response to problems of access to courts deriving from the numbers, costs and length of proceedings in the Brazilian's judicial system. This paper focuses on these alternative forms of justice, regarding domestic violence matters. Using ethnographic methods of studies at Women's Police Stations and at Small Claim Courts, the main argument is that the forms of conciliation can be very different, specifically, in these two institutions of the judicial system. The contrasts between moral values and the simbols used differently by these two institutions offer some elements for us to understand the context in which was created the Law called Maria da Penha, sanctioned on August 17th of 2006. After this Law, cases of domestic violence against women were excluded from Small Claim Courts in Brazil.
\end{abstract}

Key Words: Domestic Violence, Conciliation, Women's Police Stations, Small Claim Courts. 
No artigo intitulado "Harmonia Coerciva", Laura Nader considera que os estilos conciliatórios de solução de conflitos, que passaram a ganhar importância nos Estados Unidos a partir da década de 70, são parte de uma política de pacificação. Os anos 60 estiveram voltados para a crítica às leis, marcados pelas lutas pelos direitos civis, direitos dos consumidores, direitos ambientais, direitos da mulher. Contudo, nos últimos 30 anos, nas palavras de Laura Nader (1994:21), aquele

país teria passado de uma preocupação com a justiça para uma preocupação com a harmonia e a eficiência; de uma preocupação com a ética do certo e do errado para uma ética do tratamento.

O modelo de justiça centrado nos tribunais, cuja lógica é ter ganhadores e perdedores, foi substituído por outro, no qual o acordo e a conciliação desenham um novo contexto em que só há vencedores. O entusiasmo transformador dos anos 60, nos Estados Unidos, foi substituído por uma intolerância em relação ao conflito. Não se trata mais de evitar as causas da discórdia, mas sua manifestação. Proclamou-se que os tribunais estavam abarrotados e que os advogados e o povo norte-americano eram muito litigantes; exaltaram-se as virtudes dos mecanismos alternativos regidos pela ideologia da harmonia; e criou-se um contexto de aversão à lei e de valorização do consenso. De acordo com a autora, considerar que a harmonia é benigna é uma forma poderosa de controle social e político. Quem está errado e age em confronto com a lei é sempre o mais interessado numa solução conciliatória.

As formas de resolução de conflitos baseada na conciliação têm ganhado um interesse cada vez maior no contexto brasileiro contemporâneo e os Juizados Especiais Cíveis e Criminais são, certamente, os exemplos mais evidentes da forma como esse interesse foi institucionalizado. No entanto, é preciso reconhecer que a prática da conciliação ou os mecanismos extrajudiciais de 
Solução de conflitos e a "violência doméstica"

resolução de conflitos estão presentes, de maneira informal, há muito mais tempo em diferentes instituições do sistema de justiça como, por exemplo, nas Delegacias de Polícia e no Ministério Público. ${ }^{1}$

Opor, como propõe Nader, duas economias políticas jurídicas distintas - por um lado a que tem como base a consenso $e$, por outro, a que tem como base o conflito - é simplificar os significados políticos que os procedimentos conciliatórios podem ganhar em diferentes contextos.

Tomando como base os Juizados Especiais Criminais (JECrim) e as Delegacias de Defesa da Mulher (DDM), neste artigo mostramos que a conciliação pode ter conteúdos muito distintos quando a violência entre casais está em jogo.

Nos JECrim, a defesa da família - tida por seus agentes como uma instituição baseada em relações de afeto $e$ complementaridade de deveres e obrigações diferenciados de acordo com o gênero e a geração de seus membros - orienta os procedimentos conciliatórios, reproduzindo as hierarquias e os conflitos próprios desta instituição. As DDM, em contrapartida, criadas para defender a mulher enquanto titular de direitos civis, são uma resposta às reivindicações dos movimentos feministas empenhados em realçar as relações de poder e dominação que permeiam a vida familiar.

Essas delegacias são uma das faces mais visíveis da politização da justiça na garantia dos direitos da mulher $e$ representam uma forma de pressionar o sistema de justiça na criminalização de assuntos que eram tidos como questões privadas. $\mathrm{O}$ que não significa que as delegacias de defesa da mulher não corram o risco de novamente verem essas mesmas questões passarem por um processo de reprivatização, como, de fato, aconteceu a partir de 1995, com a criação dos JECrim.

${ }^{1}$ Sobre as delegacias de polícia ver, sobretudo, a etnografia de Kant de Lima, 1995; sobre o Ministério Público, ver Sadek, 2001. 
As etnografias realizadas antes da criação desses juizados indicam que, muitas vezes, na prática cotidiana das delegacias, ocorre uma conciliação entre vítima e agressor. ${ }^{2}$ No entanto, é importante destacar que a concepção da mulher como sujeito de direitos organiza os procedimentos adotados nessas delegacias, mesmo quando há uma reconciliação do casal. A agenda igualitária $e$ a aversão às formas de dependência pessoal orientam, inclusive, as críticas que as policiais fazem ao trabalho por elas desenvolvido ou à clientela que recorre de modo escuso às delegacias.

Para mostrar que a conciliação pode obedecer a economias morais muito distintas, a primeira parte deste artigo apresenta um conjunto de dados que apontam para o processo de feminização dos JECrim. Esses juizados mudaram a dinâmica das Delegacias da Mulher que - para surpresa de seus próprios propositores - se transformaram no lócus para onde são encaminhadas as denúncias de violência doméstica, como mostram os dados do JECrim de Campinas.

Com base no material levantado sobre as DDM localizadas em diferentes municípios de São Paulo e em análises sobre as Delegacias da Mulher em diferentes regióes do país, o segundo item mostra as mudanças ocorridas nessas delegacias especiais com a criação dos Juizados.

A terceira parte oferece um relato do modo como a violência doméstica é tratada no JECrim de Campinas. Esse quadro permite compreender os significados da luta feminista que resultou na "Lei Maria da Penha", sancionada no dia 7 de agosto 2006, retirando os delitos que envolvem violência doméstica $e$ familiar contra mulher do âmbito dos Juizados Especiais

2 Sobre as Delegacias da Mulher, ver, sobretudo, Amaral et alii, 2001; Azevedo, 1985; Ardaillon, 1989; Blay and Oliveira, 1986; Brandão, 1999; Brockson, 2006; Carrara et alii, 2002; Debert e Gregori, 2002; Debert, 2002; Grossi 1994, 1998; MacDowell dos Santos, 1999; Machado e Magalhães, 1999; Muniz, 1996; Nelson, 1996; Oliveira, 2006; Rifiotis, 2001, 2003; Saffiotti, 1995, 2002; Soares, 1999; Soares et alii, 1996; Suárez e Bandeira, 1999; Taube, 2002. 
Solução de conflitos e a "violência doméstica"

Criminais. ${ }^{3} \mathrm{Na}$ parte final do artigo apontamos para as vantagens dessa Lei, mas também para seus limites quando se pensa numa sociedade mais justa e igualitária.

\section{Os JECrim e a violência doméstica ${ }^{4}$}

Orientado pelo princípio da busca de conciliação, os JECrim foram criados pela Lei 9.099 de 1995, com objetivos centrais de ampliar o acesso da população à Justiça, promover o rápido ressarcimento da vítima $e$ acelerar as decisões penais, desafogando o Judiciário. Outro objetivo era despenalizar, oferecendo ao autor do delito, considerado de menor potencial ofensivo, a oportunidade de não ser processado criminalmente (Grinover et alli, 1997). Os profissionais do direito se referem à Lei como sendo "um benefício" concedido ao acusado.

O modelo conciliatório de solução de conflitos, que orienta esses juizados, difere do modelo acusatório clássico do direito penal brasileiro.

A Constituição de 1988, artigo 98, inciso I, inovou ao inserir na dinâmica dos juizados especiais as figuras da conciliação e da transação penal, estranhas a tradição jurídica brasileira

\footnotetext{
${ }^{3}$ A Lei 11.340/2006 recebeu o apelido de "Lei Maria da Penha" em homenagem a essa cearense tornada paraplégica pela ação criminosa do marido e que se tornou um dos exemplos mais trágicos da incidência da violência contra a mulher no país e da impunidade dos agressores. Após 19 anos do acontecimento do crime, por força da ação de grupos de defesa dos direitos humanos e feministas junto à Comissão Interamericana de Direitos Humanos da Organização dos Estados Americanos, o agressor foi punido.

${ }^{4}$ Existe uma dificuldade entre os próprios estudiosos da violência em definir o fenômeno enfrentado: ora qualifica-se como violência contra a mulher, ora como violência doméstica, violência intra-familiar, ou violência de gênero. Não há consenso. No texto utilizamos este termo fazendo referência ao tipo de violência que as delegacias de defesa da mulher recebem.
} 
(...) que seguem a tradição do direito romano, conhecida como a civil law tradition (Kant de Lima et alli, 2003:6). ${ }^{5}$

A conciliação, prevista na lei, ocorre durante uma audiência no Fórum - "Audiência Preliminar de Conciliação". Em Campinas, essas audiências ocorrem nas Varas Criminais Comuns, pois nesta cidade não existe um espaço físico reservado exclusivamente ao JECrim. Além disso, as audiências são conduzidas pelo próprio juiz titular da vara criminal ou pelo promotor, porque ainda não foi criada a figura do conciliador $e$ os mesmos profissionais que atuam nas Varas Criminais Comuns se encarregam do JECrim. ${ }^{6}$ Em outros Juizados Especiais Criminais do Estado de São Paulo a situação é semelhante, não há espaço físico reservado aos JECrim, os mesmos profissionais alternam duas lógicas distintas na condução dos delitos: nos casos de menor potencial ofensivo a conciliatória e nos crimes comuns a acusatória. Esse movimento foi denominado por Faisting (1999) de "dupla institucionalização do Poder Judiciário".

Durante a audiência de conciliação do JECrim não existe uma ação penal em andamento. Essa audiência é anterior a instauração do processo e não decide se o acusado é culpado ou não pela agressão. Isso já está presumido. Ao aceitar a pena alternativa proposta na transação penal, ao mesmo tempo, o acusado está assumindo a culpa ou o dolo.

Esses juizados foram criados para julgar os crimes chamados de menor potencial ofensivo cuja pena máxima não ultrapassa a dois anos de reclusão ${ }^{7}$ : crimes de "lesão corporal dolosa leve"

5 Sobre os Juizados Especiais Criminais ver também Amorim, 2003; Azevedo, 2000, 2001; Burgos, 2001; Campos, 2001, 2002, 2003; Cardoso de Oliveira, 1996, 2002, 2004; Faisting, 1999; Sadek, 2001; Cunha, 2001; Kant de Lima et alli, 2003; Izumino, 2003; Vianna et alli, 1999; Araújo, 2003.

${ }^{6}$ Para uma visão mais completa dos JECrim em Campinas ver Beraldo de Oliviera, 2006.

7 Até o final de 2001, os crimes de menor potencial ofensivo eram classificados como tendo pena máxima até um ano de reclusão. A partir da Lei Federal 
Solução de conflitos e a "violência doméstica"

(artigo 129 do Código Penal) e o de "ameaça" (artigo 147 do Código Penal), figuras penais mais freqüentes na tipificação da criminalidade que chega às delegacias da mulher. ${ }^{8}$

Pesquisas realizadas nos Juizados Especiais Criminais no Rio de Janeiro (Kant de Lima, Amorim e Burgos, 2003), em Porto Alegre (Campos, 2002 e Azevedo, 2000), em São Carlos (Faisting, 1999) e em São Paulo (Izumino, 2003) demonstram que a maioria dos crimes que chega a esses juizados é justamente o de "lesão corporal leve" e de "ameaça".

A pesquisa realizada no Fórum Central de Campinas, em $2001^{9}$, também mostrou que esses crimes são os que mais aparecem: $31,1 \%$ dos casos são de "lesão corporal dolosa leve" e 24,6\% de "ameaça" (tabela 1).

10.259, de 2001, que implementa os Juizados Especiais Criminais e Cíveis Federais, este conceito foi alterado, passando de um ano de reclusão para dois anos.

8 Em 2004, com a Lei 10.886, acrescentou-se o parágrafo $9^{\circ}$ ao artigo 129 lesão corporal -, tipificando a violência doméstica no Código Penal: "se a lesão for praticada contra ascendente, descendente, irmão, cônjuge ou companheiro, ou com quem conviva ou tenha convivido, ou, ainda, prevalecendo-se o agente das relações domésticas, de coabitação ou de hospitalidade. Pena de detenção, de 6 (seis) meses a 1 (um) ano". Esta Lei não alterou substancialmente a forma de tratar a violência doméstica no sistema de justiça brasileiro, pois, ao tipificar a violência doméstica em um parágrafo específico do artigo de "lesão corporal", apenas aumentou a pena mínima cominada de três para seis meses, diferenciando da "lesão corporal leve simples", mas reiterando o crime de violência doméstica como de menor potencial ofensivo, permanecendo nos Juizados Especiais Criminais. A "Lei Maria da Penha" altera a pena do parágrafo $9^{\circ}$ do artigo 129 , de modo que a pena máxima cominada seja de três anos, retirando, assim, da classificação dos crimes de menor potencial ofensivo.

9 Os dados de Campinas, utilizados neste artigo, estão em Beraldo de Oliveira, 2006. 
Guita Grin Debert e Marcella Beraldo de Oliveira

Tabela 1

Tipos penais julgados na $2^{\mathrm{a}}$ Vara Criminal do Fórum Central de Campinas pela Lei 9.099/95

\begin{tabular}{|c|c|c|}
\hline Tipo Penal & Freqüência & $\%$ \\
\hline Total* & 426 & 100 \\
\hline Lesão corporal dolosa leve & 133 & 31,1 \\
\hline Ameaça & 105 & 24,6 \\
\hline Delito de trânsito & 51 & 11,9 \\
\hline Outras contravenções penais ${ }^{10}$ & 34 & 8 \\
\hline Contra a administração & 16 & 3,7 \\
\hline Contra a honra & 12 & 2,8 \\
\hline Usurpação, esbulho e posses & 9 & 2,1 \\
\hline Periclitação da vida e da saúde & 8 & 1,9 \\
\hline Contra os costumes & 5 & 1,2 \\
\hline Lesão corporal culposa & 2 & 0,5 \\
\hline Sem informação ${ }^{11}$ & 51 & 12 \\
\hline
\end{tabular}

Fonte: Cartório da $2^{\mathrm{a}}$ Vara Criminal do Fórum Central de Campinas.

*Soma dos meses de janeiro, fevereiro, abril e maio dos anos de 2000 e 2001.

É importante destacar que dos 133 casos de "lesão corporal", indicados na tabela $1,59,4 \%$ são provenientes da Delegacia da Mulher de Campinas; dos 105 casos de ameaça, $65,7 \%$ também são enviados por esta delegacia. Isto é, a maioria dos casos de "lesão corporal" e de "ameaça" atendidos pelo JECrim não são resultado de brigas de bar, de trânsito ou, ainda, entre desconhecidos, mas são fruto de uma criminalidade na qual a vítima é mulher. Assim, os JECrim acabam por se transformar

\footnotetext{
${ }^{10}$ Essa categoria, "outras contravenções penais", inclui os crimes de "vias de fato" (art.21, CP), "perturbação do sossego" (art. 42, CP), "perturbação da tranqüilidade" (art. 65, CP) e "importunação ofensiva ao pudor (art 61, CP)".

${ }^{11}$ A tabela 1 foi construída com base nas informações do Livro de Registro de Feitos produzido pela $2^{\text {a }}$ Vara Criminal do Fórum Central; e em alguns casos, o campo destinado ao preenchimento do tipo penal encontrava-se em branco $e$ aqui aparece classificado como "sem informação".
} 
Solução de conflitos e a "violência doméstica"

em uma instância que passa a ter um papel central no atendimento à violência contra a mulher que é denunciada.

Os estudos sobre os JECrim têm mostrado, ainda, que nesses juizados a maioria dos acusados é homens e a maioria das vítimas é mulher. Em Campinas, foi possível verificar as seguintes proporções em 2001:

\section{Tabela 2}

Termos Circunstanciados de Ocorrência por sexo do autor e da vítima

\begin{tabular}{|c|c|c|c|c|}
\hline \multirow[t]{2}{*}{ SEXO } & \multicolumn{2}{|l|}{ AUTOR } & \multicolumn{2}{|l|}{ VÍTIMA } \\
\hline & $\begin{array}{l}\text { Freqüênci } \\
\text { a }\end{array}$ & $\%$ & $\begin{array}{l}\text { Freqüênci } \\
\text { a }\end{array}$ & $\%$ \\
\hline Total* & 223 & 100 & 223 & 100 \\
\hline Mulher & 21 & 9,4 & 139 & 62,3 \\
\hline Homem & 145 & 65 & 21 & 9,4 \\
\hline Mulher e Homem juntos & 7 & 3,1 & 9 & 4 \\
\hline Pessoa jurídica & 1 & 0,5 & - & - \\
\hline Sem informação & 49 & 22 & 54 & 24,2 \\
\hline
\end{tabular}

Fonte: Cartório da $2^{\mathrm{a}}$ Vara Criminal do Fórum Central de Campinas.

* Soma dos meses de janeiro, fevereiro, abril e maio do ano de 2001.

A pesquisa realizada no Rio de Janeiro por Kant de Lima, Amorim e Burgos (2003) mostrou uma proporção ainda maior de autores do sexo masculino e de vítimas do sexo feminino: $82,2 \%$ dos autores são homens e $79,9 \%$ das vítimas são mulheres. Azevedo (1999), em estudo realizado em Porto Alegre, também verificou que a maioria das vítimas nos Juizados Especiais Criminais são mulheres, correspondente a $62 \%$ do total de processos observados. No entanto, chamamos a atenção para o processo de feminização no JECrim, na medida em que as vítimas nessa instituição são mulheres e são vitimadas pelo fato de serem mulheres. 
Criados para dar celeridade à justiça, simplificando $e$ informalizando os procedimentos adotados nos crimes considerados de menor potencial ofensivo que chegavam às varas judiciais, os JECrim, para surpresa de seus propositores $e$ defensores, passaram a assumir uma demanda que, como mostraremos, raramente chegava à Justiça e que, atualmente, são canalizados para os juizados através das delegacias especiais de polícia .

A cidade de Campinas conta com 12 distritos policiais, mas a Delegacia da Mulher é a responsável pelo maior número de processos remetidos ao JECrim (tabela 3).

\section{Tabela 3}

Movimentação do JECrim no Fórum Central de Campinas de acordo com a delegacia de procedência

\begin{tabular}{l|l|r|r}
\hline \multirow{2}{*}{ Ano } & $\begin{array}{l}\text { Freqüência de } \\
\text { TCOs*** que } \\
\text { entram no Fórum }\end{array}$ & \multicolumn{2}{|l}{$\begin{array}{l}\text { TCOs provenientes } \\
\text { da DDM de }\end{array}$} \\
\cline { 3 - 4 } & & Campinas \\
\cline { 3 - 4 } & & Freqüência & \% \\
\hline Total 2000 (três meses)* & 1.637 & 746 & $\mathbf{4 5 , 6}$ \\
2001 (três meses)** & 838 & 406 & 48,5 \\
& 799 & 340 & 42,6 \\
\hline
\end{tabular}

Fonte: Distribuidor Criminal do Fórum Central de Campinas.

* meses de julho, agosto e setembro.

** meses de fevereiro, abril e maio.

*** Termos Circunstanciados de Ocorrência.

A criação dos JECrim alterou a dinâmica das delegacias: as ocorrências registradas nas Delegacias da Mulher, por exemplo, são enviadas rapidamente ao Judiciário, porque, a maioria é tipificada como "lesão corporal" e "ameaça", crimes considerados de menor potencial ofensivo que dispensam o Boletim de Ocorrência e o Inquérito Policial. Elabora-se um documento mais simplificado, o Termo Circunstanciado de Ocorrência (TCO), com 
Solução de conflitos e a "violência doméstica"

o relato dos fatos e a caracterização das partes, podendo ser encaminhado, com presteza, aos juizados (Cf. Debert, 2002).

Em Campinas, se a presença em números elevados de casos violência doméstica impressiona os agentes e estudiosos dos JECrim, fica evidente que são as Delegacias da Mulher que permitem que esse tipo de criminalidade alcance os juizados. É difícil saber se esse quadro se reproduz em outros municípios do país. Entretanto, é inegável que as DDM tiveram um papel simbólico fundamental na divulgação do fato de que agredir a esposa ou companheira é crime que será punido pela justiça.

Entretanto, o JECrim muda o significado político deste tipo de crime e nos interessa refletir sobre como essa mudança é operada.

\section{As Delegacias de Defesa da Mulher e o discurso de gênero}

Antes da Lei 9.099, você tinha a agressão, não importando o resultado dessa agressão, obrigatoriamente, sendo levada ao poder judiciário. Obrigatoriamente. (...) O que acontecia nesse meio? Acontecia que às vezes a mulher voltava à delegacia e dizia 'Pelo amor de Deus, meu problema está resolvido!' - aquela história que a gente conhece. E acontecia que às vezes, ilegalmente, a delegada, ou seja lá quem fosse, (...) sumia (...) desaparecia com o Boletim de Ocorrência. Ou fazia-se o que a lei mandava fazer e, chegando ao Ministério Público, antes do processo, [o promotor] propunha o arquivamento. Era muito comum também [o promotor] sugerir o arquivamento em nome da política criminal de manutenção da paz familiar e o juiz, mais que depressa, pááá... São todos machistas. Nenhum tem a visão de perceber que essa violência gera outra. Esquecem isso. Eles querem se livrar desse problema doméstico, que é um problema que dá trabalho. Mas, enfim, as coisas aconteciam.

O cidadão acabava sendo chamado para uma conversa, era autuado em flagrante pela Delegacia da Mulher. Ficava preso três dias, é verdade, mas ficava preso três dias. Ficar 
Guita Grin Debert e Marcella Beraldo de Oliveira

preso, nem que seja uma hora, é uma coisa que é difícil. Ele era levado à frente de uma unidade policial e tomava ciência de que aquilo que ele estava praticando era crime. Porque a primeira resposta deles é: "eu sou trabalhador, vocês estão me tratando como criminoso". "O senhor é criminoso, tanto quanto traficante, homicida". Então, tinha um efeito preventivo razoável.

Pós Lei 9.099 é possível a composição entre as partes. A Lei não foi feita para isso, foi feita para outros fins, mas levou de roldão isto - a violência doméstica. $\mathrm{E}$ o maior índice da violência doméstica é lesão leve e ameaça. A Lei prevê essa fase da composição, ela é obrigatória. E essa fase é feita porque eles não entendem nada de violência de gênero - 'Ah, meu filho, vamos parar com essa encrenca aí. Dá um ramalhete de flores para ela e está tudo resolvido'. $\mathrm{O}$ advogado quer se livrar, o cartorário quer se livrar, todo mundo quer se livrar. Ninguém é preparado em violência de gênero. Então [o agressor] não pode mais ser autuado em flagrante, os dois são levados na presença da autoridade, têm que fazer isso, têm que caminhar para essa composição.

A gente levou 12 anos fazendo aparecer que a violência doméstica era crime. De repente, isso foi banalizado. Então, os homens começaram a agredir as mulheres por conta de uma cesta básica, por conta de um ramalhete de flores "Eu vou lá, dou um ramalhete de flores para você e está tudo certo".

Eu tenho certeza, não posso provar numericamente, mas tenho certeza não que a violência doméstica aumentou, mas o grau de violência aumentou. Porque aquilo que vinha num caminhar e era inibido pela delegacia, agora tirou a inibição, caminha para a morte.

Essas críticas veementes, de uma delegada de São Paulo, aos JECrim mostram que a resolução extrajudicial de conflitos não esteve ausente das práticas das DDM, como ocorre nos demais distritos policiais. Essa forma de operar uma conciliação entre as 
Solução de conflitos e a "violência doméstica"

partes não implica, necessariamente, na prisão dos agressores por um período curto de tempo, tampouco no ato de surrupiar um boletim de ocorrência para dar um caso por encerrado. Muitas vezes, a simples enumeração dos procedimentos a serem adotados para a punição do agressor, feita pelos agentes da delegacia, pode levar à desistência da vítima de prosseguir no relato da agressão sofrida, antes mesmo de qualquer registro.

Atualmente, o Brasil conta com mais de 300 Delegacias da Mulher espalhadas em cidades de tamanho e perfil ocupacional muito diferentes. Essas DDM possuem equipamentos $e$ infraestruturas variados e gozam de um grau de prestígio diverso no sistema de segurança estadual. Com a criação das DDM, a tendência nos distritos policiais do Estado de São Paulo era encaminhar as ocorrências relacionadas aos crimes entre casais, nos quais a vítima é a mulher, para as DDM. Nesse sentido, se o sistema de segurança reconhece que agressões físicas $e$ ameaças cometidas contra a esposa são crimes, a tendência é canalizar esse tipo de ocorrência a uma delegacia especializada.

Apesar dessas diferenças, os estudos sobre as delegacias apontam várias semelhanças principalmente no que diz respeito ao público que a elas recorre e às representações das agentes da delegacia quanto às características desse público e do trabalho que desenvolvem. ${ }^{12}$

É impressionante a semelhança que os estudos revelam no tocante às representações das agentes policiais sobre razões que levam as mulheres a procurar a delegacia. Como aponta Sandra Brockson (2006), que pesquisou a DDM de São Carlos, para as agentes da delegacia, falar das mulheres em geral é assumir uma posição de solidariedade com um grupo oprimido. Por outro lado, a posição de solidariedade com o grupo raramente se mantém quando, essas mesmas agentes, narram casos específicos atendidos pela DDM. A tendência das agentes é dividir a clientela

${ }^{12}$ Ver Blay e Oliveira, 1986; Brandão, 1999; Carrara et alli, 2002; Amaral et alii, 2001; Rifiotis, 2001; Soares, 1999. 
em tipos caracterizados, de uma maneira muito sucinta. Segundo uma escrivã entrevistada por Oliveira (2006:270),

as decididas, que vão até o fim com os processos contra agressores, as que recorrem apenas ocasionalmente à DDM, pois são agredidas em virtude de circunstâncias raras dentro do contexto doméstico, $e$ as recorrentes, que sempre são agredidas, mas nunca levam até o fim sua queixa contra os parceiros.

Elaine Reis Brandão, estudando uma delegacia do Rio de Janeiro, considera que a principal razão que leva à procura da polícia é a dificuldade das mulheres de classes populares em concretizar um regime familiar tido por elas como ideal. Esse regime é caracterizado pela autora nos seguintes termos:

Ao contrário da modalidade conjugal conhecida como "casal moderno", encontrada em certos segmentos das camadas médias, parece haver nas classes trabalhadoras uma forte demarcação dos papéis conjugais, valorados diferencial e hierarquicamente, segundo os padrões de moralidade das redes de parentesco e de localidade (Brandão, 1999: 60).

Segundo a autora, o recurso à polícia seria um meio de promover o reajustamento do parceiro à expectativa social predominante nas camadas populares, de modo que essas mulheres passam a delegar à autoridade policial a tarefa de corrigir os homens acusados de agressão e de inadequação aos papéis conjugais esperados.

$\mathrm{O}$ atendimento a esse tipo de demanda é motivo de desconforto para os agentes da delegacia que vêem, nesses casos, um desvirtuamento de seu papel policial em nome de práticas que estariam relacionadas a um trabalho de assistente social. Como aponta uma policial: 
Solução de conflitos e a "violência doméstica"

As populações de baixa renda e baixo nível escolar são as que mais recorrem à DDM, pois acham que tudo se resolve na delegacia (...) muitas mulheres vão também à DDM para desabafar, contam suas histórias, mas não querem que fique nada registrado. (...) É grande o número de mulheres que recorrem à DDM para buscar orientação ou para assustar os parceiros agressores.

A literatura sobre o tema mostra, ainda, que a tendência dos agentes policiais é responsabilizar a clientela pelo desvirtuamento do trabalho policial e pela monotonia do cotidiano nas delegacias, porque o trabalho de investigação - que, na opinião das agentes, é o que dá entusiasmo à prática policial para a qual foram treinadas - é substituído pela conciliação das partes em conflito, num contexto em que boa parte das vítimas tem aversão à punição dos culpados. Além disso, as pesquisas enfatizam que há um acordo entre os agentes na consideração da ineficácia, a médio e longo prazo, da conciliação feita na delegacia.

Brandão (1999:124-125) aponta que as agentes da delegacia do Rio de Janeiro estão conscientes do alto grau de recorrência das agressões que levam a uma volta das vítimas à delegacia. Com muita sensibilidade, a autora diz que é praxe que os detetives orientem as mulheres para que voltem à delegacia caso seja necessário, tranqüilizando, momentaneamente, a vítima receosa de suspender o B.O. Contudo, paradoxalmente, quando a vítima volta, ela acaba sendo repreendida pela suspensão anterior, "vamos ver se desta vez você prossegue", diz a policial, repreendendo uma das mulheres que retornaram à delegacia para registrar o mesmo tipo de ocorrência. Os agentes da polícia consideram que essas mulheres estão brincando com o aparato público, são coniventes com os agressores e com a situação de violência da qual são vítimas.

Assim, as mulheres que desistem são vistas como uma espécie de cidadãs que não souberam se apoderar de seus direitos, seja por uma ignorância intransponível, seja por um déficit moral de caráter. 
A visão das agentes sobre as razões que estariam levando boa parte das mulheres a recorrer à delegacia, por um lado, e a percepção que elas têm da desconfiança em relação à polícia que reina nas demais esferas do sistema da justiça criminal, por outro, oferecem uma dinâmica específica aos procedimentos adotados nas DDM: independente das características do município, do tipo de equipamento e dos recursos humanos disponíveis, a maioria das queixas é tipificada como "lesão corporal leve" e "ameaça" e, como vimos, são encaminhadas aos juizados especiais criminais.

As agentes das DDM sabem que a família é uma instituição violenta e, muitas vezes, elas mesmas se colocam como vítimas dessa violência. É comum ouvir relatos de agentes afirmando que eram "escravizadas" pelos maridos, "exímia piloto de tanque e de fogão e de filho"; "vítima da violência doméstica surda". Nesses casos, a busca de um trabalho remunerado é vista como a melhor forma de ganhar autonomia e ser uma mulher independente (cf. Debert, 2002). Em análise cuidadosa, na qual avalia o grau de influência do discurso feminista sobre a cultura jurídica das policias, MacDowell Santos (1999) mostra que essa influência - no Estado de São Paulo, pioneiro na criação dessas instituições, com 126 delegacias funcionando na capital e no interior - tem variado de acordo com a conjuntura política. No momento da criação das delegacias, a relação com o movimento era intensa e o discurso feminista era predominante. Em outros momentos essa relação se desfez, contudo, a autora identifica na sua pesquisa uma apropriação, por parte das agentes, de um discurso de gênero, sem evidenciar a aliança com o movimento feminista.

Ressaltamos essa apropriação, porque ela envolve a percepção da mulher como um sujeito de direitos. Essa visão organiza, também, as concepções sobre o que seria o ideal do trabalho a ser realizado por uma delegacia de defesa da mulher, bem como a decepção com a maneira pela qual esse trabalho está, de fato, sendo realizado, dado o tipo de demanda que chega à instituição. 
Solução de conflitos e a "violência doméstica"

A apropriação do discurso de gênero é feita de modo específico quando combinada com o ethos profissional policial. Contudo, o modo como agentes da polícia percebem a violência embutida no contrato conjugal e na família oferece um conteúdo específico e diferente dos procedimentos adotados nos JECrim.

\section{A conciliação no JECrim}

Tratar a violência contra a mulher no judiciário na lógica conciliatória traz conseqüências singulares. A Lei 9.009/95 dispõe que o autor do delito de menor potencial ofensivo só poderá ser beneficiado com a transação penal (geralmente, pagamento de uma cesta básica) uma única vez no período de cinco anos. Contudo, a reincidência não está ausente das agressões entre casais. Alguns agentes do JECrim, assim como da Delegacia da Mulher, têm consciência deste fato $e$ da inadequação do procedimento adotado pelos juizados no tratamento dos agressores reincidentes. Segundo uma advogada que atua no JECrim:

Esse modelo conciliatório não é o melhor modelo para tratar esse tipo de criminalidade, pois o marido reincide, ele não tem medo, ele obriga a mulher, até piora a situação da mulher recorrer à justiça (...) eu tenho um cliente que já está beneficiado quatro vezes com cesta básica, duas em menos de seis meses, às vezes na mesma Vara Criminal. A mulher procurou e quebrou a cara! Ela não volta mais à justiça!

Porém, diferentemente do que ocorre com a reincidência nas delegacias, onde a delegada indignada diz para a vítima "vamos ver se desta vez você prossegue", no Juizado Criminal de Campinas, os diferentes agentes tentam induzir a vítima à nãorepresentação. ${ }^{13}$

${ }^{13}$ Kant de Lima et alli (2003:12-13), que pesquisaram dois Juizados Especiais Criminais na cidade do Rio de Janeiro, observaram um alto percentual de desistência das vítimas. Porém, os pesquisadores mostram que este percentual 
Numa das audiências no Fórum Central de Campinas, relatadas por Beraldo de Oliveira (2006), o agressor passava pela segunda vez por uma audiência de conciliação do JECrim num período inferior a cinco anos, como verificado nos autos. A primeira audiência ocorreu no ano anterior, por crime de "lesão corporal" contra uma vítima diferente da atual. O desfecho anterior foi a transação penal. $\mathrm{O}$ autor encontrava-se novamente na mesma situação: vítima mulher e crime de "lesão corporal" enviado pela DDM. No corredor de espera da sala de audiência, a atual vítima, que não estava mais morando com ele, comenta seu interesse em prosseguir com o caso:

Quero ir até o final com isso, quando a gente começa alguma coisa, tem que ir até o fim.

[No entanto, o juiz inicia a audiência dizendo]

Temos aqui um caso de lesão corporal vindo da delegacia da mulher. As versões sobre o fato relatado na delegacia são versões conflitantes. Não posso saber como ocorreu realmente. Não estava lá para saber. Tudo bem que temos o exame do IML para provar que houve lesão, mas não temos testemunhas para saber como ocorreu. Não tenho como saber quem está certo, é a sua versão contra a dela. Antes de tudo, quero explicar que se esse caso for levado adiante, as conseqüências não serão muito bombásticas. Além disso, vocês com idade superior a minha, deveriam

apresenta uma enorme variação entre os juizados estudados. Em um deles, o índice é superior a $50 \%$, no outro não passa de $25 \%$. Os autores afirmam que essa diferença se deve principalmente ao fato de o primeiro ter priorizado a celeridade, medida na estatística do Tribunal pela capacidade de encerrar processos. No outro Juizado prevalece uma orientação para que os conciliadores evitem a desistência, porque um índice elevado de desistência seria percebido como fracasso do trabalho da instituição, na medida em que não teria qualquer repercussão sobre o conflito $e$, portanto, sobre a pacificação das relações de violência, contrariando, segundo a compreensão ali reinante, um dos objetivos maiores do JECrim. Essa pesquisa mostra que não podemos generalizar a atitude dos operadores do direito em todos os juizados, mas é importante destacar o impacto da não-representação nos casos de agressões entre casais. 
Solução de conflitos e a "violência doméstica"

saber resolver isto sozinhos. Acho uma atitude correta ir até a DDM, nada justifica ele agredir a senhora, mas é um caso que se for levado pra frente só trará mais dor de cabeça.

A procuradora do Estado, no meio da audiência, talvez percebendo o espanto do pesquisador, que ela sabia estar pesquisando violência doméstica, comentou:

A vítima deve desistir e é isso que o juiz está tentando fazer. Se ela continuar, ele terá que ser denunciado pelo Ministério Público, porque não pode ser beneficiado novamente com a cesta básica (...). E, aí, se o processo for iniciado, ela poderá ser processada por falso depoimento $e$ ela não está sabendo disso! Pois não há provas de que ele bateu nela, não há testemunhas (...). É ela que vai se dar mal no processo!

[A vítima finalmente desiste de representar e fala para o juiz]

Eu quero que fique claro que estou desistindo, mas poderia continuar, que essa é uma escolha minha. Quero que ele saiba disso!

Assim, a audiência de conciliação pode ser transformada num espaço privilegiado para a indução das vítimas a desistirem da causa levada à Justiça. Na etapa da conciliação se torna possível a acolhida e, ao mesmo tempo, a retirada da violência doméstica do Judiciário. As pesquisas sobre os JECrim apontam que a maioria dos crimes que entram neste procedimento conciliatório não se transforma em processo penal. ${ }^{14} \mathrm{~A}$ indução à

\footnotetext{
${ }^{14}$ As pesquisas realizadas nos JECrims de outros estados demonstram que o desfecho dos processos nos Juizados são, principalmente, o da desistência. A pesquisa realizada por Kant de Lima, Amorim e Burgos (2003: 10) no Rio de Janeiro mostra que $4,6 \%$ dos processos são encerrados em audiência de instrução e julgamento, $33,2 \%$ dos litígios são resolvidos através de composição cível, 22,9\% através de transação penal e 39,3\% pela desistência. Em Porto Alegre, Azevedo (2001:104) demonstra que a renúncia, ou a não-representação
} 
não-representação é uma forma de retirar, definitivamente, o caráter propriamente criminoso dos crimes que ocorrem no espaço doméstico.

Os casos enviados pelas Delegacias da Mulher para os Juizados são caracterizados pelos seus agentes como de caráter mais "social" do que "criminal". Nesse sentido, os acusados não seriam propriamente criminosos. O que está em questão não é a diferença entre as agressões sofridas, mais ou menos graves, mas a posição que esse tipo de crime ocupa na hierarquia da criminalidade em geral.

Um promotor entrevistado caracteriza a agressão entre casais nos seguintes termos:

O problema é que isso é um problema social e não legal! Casos desse tipo a vítima tem que denunciar várias vezes para o cara começar a pensar em mudar. Não é a primeira vez que ele vem aqui, passa por uma audiência e então tudo mudou. Ele não vai mais bater. Isso não ocorre. Além disso, a vítima já passou por muitas brigas até chegar aqui.

A condução desses casos no juizado é permeada por ambigüidades: o promotor diz que para mudar a situação da vítima é necessário "denunciar isso várias vezes" e, ao mesmo tempo, tenta fazer com que ela desista de prosseguir se o agressor é reincidente, já que, nesse caso, uma ação penal poderia ser iniciada.

é muito mais freqüente nos JECrim POA do que a transação penal ou conciliação. Mas que a decisão terminativa desses juizados, em maior número nos anos de 1996 e 1997, é o arquivamento. Em São Paulo, Izumino (2003: 299) observou que em 44,4\% dos casos o tipo de decisão, entre 1999 e 2003, a extinção de punibilidade, o que se refere principalmente à decisão da vítima não representar criminalmente. Não é novidade o fato da maior parte das ocorrências terem sido encerradas dessa maneira, desfecho mais comum apontado por todas as pesquisas (Azevedo, 2000; Viana, 1999; Kant de Lima, 2003; Faisting, 1999; Campos, 2001; Hermann, 2000). 
Solução de conflitos e a "violência doméstica"

Minimizar a importância da reincidência e induzir a mulher a não-representar contra seu agressor é invisibilizar a violência doméstica no Judiciário. Apesar dos agentes, em entrevistas, não duvidarem que bater em mulher é crime, o modo de tratar essa criminalidade no JECrim devolve o fato delituoso para ser solucionado no âmbito familiar.

As audiências de conciliação no JECrim de Campinas são geralmente muito rápidas, não ultrapassando dez minutos. A proposta de transação penal é quase sempre o pagamento de uma cesta básica para uma instituição de caridade.

Os próprios juizes reconhecem que essa pena pode significar uma banalização da punição da violência contra a mulher. Segundo o juiz da $3^{\text {a }}$ Vara Criminal de Campinas: "Uma vez, um desses maridos me disse: 'eu tenho então que pagar uma cesta básica? Se eu soubesse que era tão barato bater na minha mulher teria batido mais vezes".

As delegacias dão visibilidade ao fato de que a violência contra a mulher é crime. Os JECrim operam de forma inversa, reprivatizando a violência doméstica. Essas duas instituições, criadas com objetivos diferentes, atuam de forma distinta ante o conflito doméstico e abrigam agentes com concepções diferenciadas sobre a mulher e sobre a família, como pode ser observado no relato de uma audiência em Campinas:

[No Fórum Regional de Vila Mimosa o porteiro chamou as partes pelo nome e orientou-as a entrarem na sala de audiência. A mulher, muito gorda, entra na sala de audiências, espalhafatosamente, arrastando as cadeiras e chamando atenção de todos, que olhavam de maneira jocosa para ela. Em seguida entra o marido. Sentam-se à mesa, marido e esposa. O promotor, que conduz a audiência, pergunta para a vítima]

A senhora quer dar uma chance para ele?

[Ela responde prontamente e bem alto]

Quero sim! 
Guita Grin Debert e Marcella Beraldo de Oliveira

[O marido fala para o promotor]

Eu não fiz nada para ela, é tudo mentira!

A mulher não se defende e confirma a desistência em prosseguir com o caso. As partes assinam o termo de renúncia $e$ saem da sala. Logo em seguida, o promotor faz um comentário ao procurador do estado: "É claro que ela ia desistir, quem vai querer ficar com essa mulher? Se separar deste, não arruma outro nunca!".

$\mathrm{Na}$ atuação desses profissionais durante a audiência de conciliação, observada no JECrim de Campinas, parece que ter um marido é o desejo natural da mulher, independente do modo como esse papel social é desempenhado. Essa concepção dos desejos naturais da mulher fica ainda mais evidente nas palavras de uma advogada de Campinas, atuante nos JECrim:

Se eu sou advogada do homem, vamos pagar uma cesta básica e acabou. Se eu sou advogada da mulher, vou agir de outra forma. Eu tenho, nos meus trinta anos de advocacia, boa formação, não só eu, como vários advogados que eu conheço, tento conciliar o casal. Conversar com o marido, conversar com a mulher, eu falo: "leva a tua mulher para tomar cerveja", a mulher fala "mas eu não gosto", aprende a gostar, vai junto com teu marido, é teu companheiro! Ele gosta de pescar, vai pescar junto! Cative, ganhe a confiança dele! Porque é que vocês não estão se dando bem? "Porque eu chego em casa, minha mulher está fedida, cheirando a alho, cebola, desarrumada e coisa e tal!" Então você tem que chamar a mulher e dizer, "Olha, não é bem por aî". E ela fala "Mas como é que eu vou me arrumar, não tenho tempo". Bom, a parte pior é da gente mesmo! Sempre! Então você tem que tentar conciliar de uma forma que você cative o seu marido. É esse o único caminho! Não tem outro! É fazer com que a mulher use a cabeça, conquiste o marido, seja a companheira dele e carregue a pedra sozinha. Aí ela vai ter um casamento duradouro, e razoável! 
Solução de conflitos e a "violência doméstica"

A visão estereotipada do significado da conciliação expressa pela advogada está em sintonia com a pressa em dar um desfecho para o caso, que parece não merecer uma atenção da justiça, porque deveria ser resolvido no cotidiano da vida familiar, que deve ser preservada - esse é o desejo de todos, da esposa, da justiça e do marido.

Em artigo do jornal Zero Hora (21/07/2001:3), a Desembargadora Dra. Maria Berenice Dias, do Tribunal de Justiça do Rio Grande do Sul, aponta, com razão, as armadilhas criadas pela necessidade de representação da vítima nos casos de crimes entre casais:

Não foi dada atenção merecida ao fato de a Lei $\mathrm{n}^{\circ}$. 9.099/95, ao criar os juizados especiais, ter condicionado o delito de lesão corporal leve e culposa à representação do ofendido. Com isso, omitiu-se o Estado de sua obrigação de agir, transmitindo à vítima de buscar a punição de seu agressor, segundo critério de mera conveniência. Ora, em se tratando de delitos domésticos, tal delegação praticamente inibe o desencadeamento da ação quando o agressor é marido ou companheiro da vítima. De outro lado, quando existe algum vínculo entre a ofendida e seu agressor, sob a justificativa da necessidade de garantir a harmonia familiar [grifo nosso], é alto o índice de absolvições, parecendo dispor de menor lesividade os ilícitos de âmbito doméstico, quase se podendo dizer que se tornaram crimes invisíveis. Mas tudo isso não basta para evidenciar que a Justiça mantém um viés discriminatório $e$ preconceituoso quando a vítima é mulher.

No JECrim, não importa a defesa da mulher enquanto sujeito de direitos, mas a preservação da família e da relação marido e mulher. Dessa forma, essa instituição reifica a hierarquia entre casais de modo a não importunar o trabalho da Justiça.

Juizes ou promotores, sensíveis às agressões e ao modo como as mulheres são tratadas por seus companheiros, tendem a 
repreender o acusado, impondo-se uma espécie de função missionária, no sentido de estabelecer as regras que devem orientar o convívio entre marido e mulher.

Durante uma audiência de lesão corporal na $1^{\text {a }}$ Vara Criminal do Fórum Central de Campinas, após a vítima ter manifestado sua desistência em prosseguir com o caso, a promotora, sentada de frente para o agressor, olhou-o fixamente $e$, de modo incisivo, disse: "O senhor deveria agradecer à sua mulher por ter desistido de prosseguir com este caso. Ela está sendo muito generosa com o senhor por não-representar. Não bata mais nela, viu!".

Os operadores do direito, raramente, reconhecem que esse é um crime altamente sexualizado, no qual prevalecem a hierarquia de gênero e os preconceitos, ou seja, que a maioria das vítimas desses crimes são as mulheres e que são vitimadas simplesmente pelo fato de serem mulheres! Desse modo, a violência contra a mulher ganha novamente invisibilidade. "Eles é que devem resolver o problema deles. Só deveriam recorrer se fosse caso de lesão grave" - diz um juiz entrevistado, considerando que um problema familiar deve ser resolvido em casa. A mulher não é pensada como sujeito de direitos, diferente da DDM, onde lhe perguntam se ela irá ou não exercer seus direitos. O que importa é a conciliação do casal, que implica a dissolução da figura de vítima e de réu, em que a vítima está litigando pela punição de um crime no qual foi lesada. No caso da violência entre casais, a família é interpelada para resolver um problema que não deveria ter chegado ao âmbito do Judiciário.

Os agentes do JECrim sabem que a justiça não pode criar a boa família. O importante é que esses crimes saiam da esfera do Judiciário para não emperrar o julgamento de crimes considerados mais importantes. 
Solução de conflitos e a "violência doméstica"

\section{A conciliação e as economias políticas jurídicas}

Carmem de Campos mostra, com razão, que a ausência de um paradigma de gênero leva à banalização da violência doméstica no JECrim e à reprivatização do conflito, porque devolve o poder ao agressor. No entanto, segundo a autora, a

Lei 9.099/95 não inaugura um procedimento novo, apenas desloca a conciliação informal da Delegacia de Polícia para o Poder Judiciário, dotando-lhe de caráter formal, por ser agora feita frente ao juiz que tem poderes legalmente constituídos para tal (Campos, 2002:20).

Neste artigo, procuramos mostrar que no fluxo do processo da delegacia aos juizados está envolvido um deslocamento muito maior do que se poderia imaginar. Não se trata apenas de locais diferentes em que a conciliação pode ocorrer, da força do poder legal de delegados e de juizes ou do poder simbólico que cada um deles exerce sobre a clientela que recorre ao sistema de justiça. Ao contrário, nesse processo há uma mudança radical nos atores envolvidos, nas ações descritas e na lógica que orienta a solução do conflito nelas envolvidos.

A vítima de sujeito de direitos é constituída em esposa ou companheira; da mesma forma que o agressor passa a ser marido ou companheiro. O crime se transforma em um problema social ou em déficit de caráter moral dos envolvidos que, na visão da justiça, pode ser facilmente corrigido através do esclarecimento $e$, nos casos mais difíceis, pode ser compensado com uma pequena pena. A lógica que orienta a conciliação nos juizados implica em uma solução rápida, simples, informal e econômica para os casos que não deveriam ocupar espaço no Judiciário, tampouco o tempo de seus agentes.

As pesquisas sobre as delegacias têm demonstrando que o recurso das vítimas à delegacia pode levar a uma conciliação, mesmo que temporária, do casal. Contudo, procuramos mostrar 
que essas distintas economias morais estão em jogo nas $\operatorname{DDM} e$ nos JECrim.

Centrada na questão da "violência contra a mulher", as delegacias foram criadas para responder a demanda de um sujeito de direitos e suas agentes são capazes de se indignar com o fato de a mulher abrir mão do exercício destes direitos. Já o juiz no JECrim, apesar de ter um poder simbólico maior do que o das delegadas, não foi formado, não está preparado, nem se espera que ele esteja atento para a questão da "violência contra a mulher", mesmo que, na prática, esse tipo de criminalidade seja recorrente, como mostram os dados apresentados sobre o JECrim de Campinas. A percepção do juiz sobre o que é a família e sobre a importância do seu papel social orientam as decisões tomadas no JECrim.

A indignação com o modo pelo qual a violência doméstica era tratada e a visão de que esse crime merece um tratamento diferenciado fez com que os movimentos feministas reivindicassem mudanças que levaram à promulgação da Lei $n^{\circ} 11.340$ de 07 de agosto de 2006, apelidada de "Lei Maria da Penha". Como descrito no Artigo $1^{\circ}$, essa Lei

dispõe sobre a criação dos Juizados de Violência Doméstica e Familiar contra a Mulher e estabelece medidas de assistência e proteção às mulheres em situação de violência doméstica e familiar.

A Lei alterou o tratamento dos crimes de violência doméstica contra a mulher ${ }^{15}$ no sistema de justiça. Entre as alterações, num primeiro momento, destacam-se: o aumento da pena máxima, que passa a ser de três anos de detenção, o que retira essa violência do rol dos crimes de menor potencial ofensivo, não sendo mais enviada aos Juizados Especiais Criminais; passa a admitir a prisão em flagrante para os casos de

${ }^{15}$ Crime disposto no artigo $129, \S 9^{\circ}$, do Código Penal. 
Solução de conflitos e a "violência doméstica"

violência doméstica contra a mulher; impede a aplicação de pena de cesta básica e passa a exigir novamente - como antes da Lei 9.099/95 - a instauração do inquérito policial. Espera-se que essas alterações restituam às delegacias práticas que eram realizadas antes da Lei de 1995, criando condições para que elas possam ser executadas a contento.

Os novos Juizados de Violência Doméstica e Familiar contra a Mulher são fruto de uma politização da justiça. Mas, diferente das DDM, o foco dos Juizados criados pela Lei Maria da Penha recaiu sobre a família, sobre a violência contra a mulher somente no contexto doméstico e familiar. Como será a atuação desses juizados na defesa dos direitos da mulher? Essa questão que merece atenção. É a mulher como sujeito de direitos ou são as formas esperadas no desempenho por homens e mulheres do script familiar que orientarão as decisões dos juizes? Qualquer resposta generalizante seria apressada, dada as diferenças que marcam o país e a atuação das diferentes esferas do sistema de justiça. Contudo, a nova Lei está centrada na violência contra a mulher nas relações de conjugalidade e familiar, retirando do âmbito dessas instituições a violência impetrada contra as mulheres, pelo fato de ser mulher, nos espaços públicos, nas relações de trabalho, entre outras.

\section{Referências bibliográficas}

AmARAL, C.G. et alli. Dores Invisíveis: Violência em Delegacias da Mulher no Nordeste. Fortaleza, Edições Rede Feminista Norte e Nordeste de Estudos e Pesquisas sobre a Mulher e Relações de Gênero (REDOR), 2001.

AmoRIM, M. S. Cidadania e jurisdição de direitos nos Juizados Especiais Criminais. In: AMORIM, M. S.; KANT DE LiMA, R.; BuRGOS, M. B. (orgs.) Juizados Especiais Criminais, sistema judicial e sociedade no Brasil: ensaios interdisciplinares. Niterói, Intertexto, 2003, pp.205-229.

ARAÚJO, L. F. Violência contra a mulher: a ineficácia da justiça penal consensuada. Campinas/São Paulo, CS/Lex, 2003. 
ARDAILLON, D. Estado e Mulher: Conselhos dos Direitos da Mulher e Delegacias de Defesa da Mulher. São Paulo, Fundação Carlos Chagas, mimeo., 1989.

e DEBERT, G.G. Quando a vítima é mulher - Análise de julgamentos de crimes de estupro, espancamento e homicídio. Brasília, Conselho Nacional dos Direitos da Mulher, 1987.

Azevedo, M. A. Mulheres Espancadas: A Violência Denunciada. São Paulo, Cortez, 1985.

AzEVEDO, R. G. Informalização da Justiça e Controle Social - Estudo Sociológico da Implementação dos Juizados Especiais Criminais em Porto Alegre. São Paulo, IBCCRIM, 2000.

Juizados Especiais Criminais: Uma abordagem sociológica sobre a informalização da justiça penal no Brasil. Revista Brasileira de Ciências Sociais, vol. 16, nº 47, outubro de 2001.

BERALDO DE OliveIRA, M. Crime Invisível: a Mudança de Significados da Violência de Gênero no Juizado Especial Criminal. Dissertação de Mestrado, Departamento de Antropologia Social, Instituto de Filosofia e Ciências Humanas/UNICAMP, 2006.

BLAY, E. e OliveIRA, M. Em briga de Marido e Mulher... Rio de Janeiro/ São Paulo, IDAC/Conselho da Condição Feminina, 1986.

BRANDÃo, E. Violência Conjugal e o Recurso Feminino à Polícia. In: Bruschini, C. e Hollanda, H. B. (orgs.) Horizontes Plurais. São Paulo, Fundação Carlos Chagas/Editora 34, 1999.

Brockson, S. A Delegacia de Defesa da Mulher de São Carlos, SP. In: Debert, G. G. et alii. Gênero e Distribuição da Justiça: as Delegacias de Defesa da Mulher e a construção das diferenças. Campinas-SP, Núcleo de Estudos de Gênero - Pagu/UNICAMP, Coleção Encontros, 2006.

BuRGOS, M. B. Conflito e sociabilidade: a administração da violência pelos Juizados Especiais Criminais. Cidadania e Justiça: revista da AMB, ano 5, n 10, Rio de Janeiro, $1^{\circ}$ sem. 2001, pp.222-235.

CAMPOS, C. H. A violência doméstica no espaço da lei. In: BRUSCHINI, C.; PINTO, C. R. (orgs.) Horizontes Plurais: novos estudos de gênero no Brasil. São Paulo, Editora 34/Fundação Carlos Chagas, 2001, pp.301-322. 
Solução de conflitos e a "violência doméstica"

Justiça Consensual e Violência Doméstica. Textos Bem

Ditos, vol. 1, Porto Alegre, Themis, 2002.

Juizados Especiais Criminais e seu déficit teórico. Estudos

Feministas, 11(1)336, Florianópolis, UFSC, jan-jun de 2003, pp.155170.

CARDoso DE Oliveira, L. R. Entre o justo e o solidário: Os dilemas dos direitos de cidadania no Brasil e nos EUA. Revista Brasileira de Ciências Sociais (ANPOCS), ano 11, nº 31, 1996, pp.67-81.

Direito Legal e Insulto Moral - Dilemas da cidadania no Brasil, Quebec e EUA. Rio de Janeiro, Relume Dumará, 2002. 344, mimeo., 2004.

. Honra, Dignidade e Reciprocidade. Série Antropologia, $n^{\circ}$

CARRARA, S. et alli. "Crimes de Bagatela": a violência contra a mulher na justiça do Rio de Janeiro. In: CORRÊA, M. (org.) Gênero e Cidadania. Campinas, Núcleo de Estudos de Gênero - Pagu/Unicamp, Coleção Encontros, 2002.

CunHA, L. G. S. Juizado Especial: ampliação do acesso à justiça? In: SADEK, M. T. (org.) Acesso à Justiça. São Paulo, Fundação Konrad Adenauer, 2001.

Debert, G. G. e Gregori, M. F. As Delegacias Especiais de Polícia e o Projeto Gênero e Cidadania. In: CORRÊA, M. (org.) Gênero e Cidadania. Campinas, Núcleo de Estudos de Gênero Pagu/Unicamp, Coleção Encontros, 2002, pp.9-19.

DEBERT, G.G. A família e as novas políticas sociais no contexto brasileiro. Interseções - Revista de Estudos Interdisciplinares, ano 3, n 2 , UERJ, 2001.

Arenas de Conflitos Éticos nas Delegacias Especiais de Polícia. Primeira Versão, no 114, IFCH/Unicamp, Novembro de 2002.

FAISTING, A L. O dilema da Dupla Institucionalização do Poder Judiciário: O Caso do Juizado Especial de Pequenas Causas. In: SADEK, M. T. (org.) O Sistema de Justiça. São Paulo, Editora Sumaré, 1999.

Grinover, A. P.; Gomes Filho, A. M.; Fernandes, A. S.; Gomes, L. F. Juizados Especiais Criminais - Comentários à Lei 9099. 2ª ed. São Paulo, Editora Revista dos Tribunais, 1997. 
Grossi, M. P. Vítimas ou Cúmplices? Dos diferentes Caminhos da Produção Acadêmica sobre Violência contra a Mulher no Brasil, São Paulo, ANPOCS, mimeo., 1991.

Novas/Velhas Violências contra a Mulher no Brasil. Estudos Feministas, vol. 2, 1994.

Rimando Amor e Dor: Reflexões sobre a violência no vínculo afetivo conjugal. In: PEDRO, J. e GROSSI, M. P. (orgs.) Masculino, Feminino, Plural. Florianópolis, Ed. Mulheres, 1998.

HERMANN, L. Violência Doméstica: a dor que a lei esqueceu. Considerações sobre a lei 9099/95. Campinas, Cel-Lex Editora, 2000.

IZUMINO, W. P. Justiça para todos: os Juizados Especiais Criminais e a violência de gênero. Tese de Doutorado, Departamento de Sociologia da Faculdade de Filosofia, Letras e Ciências Humanas da USP, 2003.

Justiça Criminal e Violência contra a Mulher - O Papel do Judiciário na Resolução dos Conflitos de Gênero. Dissertação de Mestrado, FFLCH/USP, 1997.

KANT DE LIMA, R. et alli. A violência doméstica nos Juizados Especiais Criminais: desafios para o direito e para os tribunais brasileiros. 2003, (www.uff.br/nufep/paginas/aba.htm).

L'administration de la violence quotidienne au Brésil. L'experience de Tribunaux criminels spécialisés. Droit e Culture Revue Semestrielle d'anthropologie et d'histoire, n. hors série, 2001.

KANT DE LimA, R. A Polícia da Cidade do Rio de Janeiro: seus dilemas e paradoxos. Rio de Janeiro, Editora Forense, 1995.

Macdowell Santos, C. Cidadania de Gênero Contraditória: Queixas, Crimes e Direitos na Delegacia da Mulher de São Paulo. In: AmARAL, A. J. e PERRONE-MoISÉs, C. (orgs.) O Cinqüentenário da Declaração Universal dos Direitos do Homem. São Paulo, Editora da USP, 1999.

MACHADO, L. Z. E.; MAGALHÃES, M. T. B. Violência Conjugal: os Espelhos e as Marcas. In: SuÁrEZ, M. e BANDEIRA, L. M. (eds.) Violência, Gênero e Crime no Distrito Federal. Brasilia, EDUnB/Ed. Paralelo 15, 1999.

Muniz, J. Os Direitos dos Outros e os Outros Direitos: Um Estudo sobre a Negociação de Conflitos das DEAMs/RJ. In: SOARES, L. E. (ed.) Violência e Política no Rio de Janeiro. Rio de Janeiro, ISER/Relume Dumará, 1996. 
Solução de conflitos e a "violência doméstica"

NADER, L. Harmonia Coerciva: a economia política dos modelos jurídicos. Revista Brasileira de Ciências Sociais, ano 9, n 29, 1994, pp.18-29.

Nelson, S. Constructing and Negotiating Gender in Women's Police Stations in Brazil. Latin American Perspectives, vol. 23, nº 1, 1996.

Oliveira, P. A Delegacia de Defesa da Mulher em São José do Rio Pardo. In: DEBERT, G.G. et alii. Gênero e Distribuição da Justiça: as Delegacias de Defesa da Mulher e a construção das diferenças. Campinas-SP, Núcleo de Estudos de Gênero - Pagu/Unicamp, Coleção Encontros, 2006.

RifIOTIS, T. As Delegacias Especiais de Proteção à Mulher no Brasil e a "judicialização" dos conflitos conjugais. Mimeo., 2001.

As Delegacias Especiais de Proteção à Mulher no Brasil e a "judicialização" dos conflitos conjugais. Anuário 2003. Direito e Globalização. Atas do Seminário do GEDIM, Universidade Cândido Mendes, Rio de Janeiro, Editora Lumen Juris/UNESCO/MOST, 2003, pp.381-409.

SADEK, M. T. Acesso à Justiça. São Paulo, Fundação Konrad Adenauer, 2001.

SAFFIOTI, H. I. B. Violência Doméstica: questão de polícia e da sociedade. In: Corrêa, M. (org.) Gênero e Cidadania. Campinas-SP, Núcleo de Estudos de Gênero - Pagu/Unicamp, Coleção Encontros, 2002.

e Almeida, S. S. Violência de Gênero: Poder e Impotência. Rio de Janeiro, Revinter, 1995.

SOARES, B. M. Mulheres Invisíveis: violência conjugal e as novas políticas de segurança. Rio de Janeiro, Ed. Civilização Brasileira, 1999.

SOARES, L. E. et alli. Violência e Política no Rio de Janeiro. Rio de Janeiro, Relume Dumar/ISER, 1996.

SuÁREZ, M. e BANDEIRA, L.M. (eds.) Violência, Gênero e Crime no Distrito Federal. Brasilia, EDUnB/Ed. Paralelo 15, 1999.

A Politização da Violência Contra a Mulher e o Fortalecimento da Cidadania. Série Sociológica, no 191, Brasília-DF, UnB, 2001. 
Guita Grin Debert e Marcella Beraldo de Oliveira

TAUBE, M. J. Quebrando Silêncios, Construindo mudanças. In: CORRÊA, M. (org.) Gênero e Cidadania. Campinas-SP, Núcleo de Estudos de Gênero - Pagu/Unicamp, Coleção Encontros, 2002.

Vianna, L. W. et alli. A Judicialiazação da Política e das relações sociais no Brasil. Rio de Janeiro, Ed. Renavan, 1999. 